\title{
Practical issues in uterine pathology from banal to bewildering: the remarkable spectrum of smooth muscle neoplasia
}

\author{
Esther Oliva
}

\author{
Department of Pathology, Massachusetts General Hospital, Boston, MA, USA
}

\begin{abstract}
Among mesenchymal tumors of the uterus, smooth muscle neoplasms are most common. The wide morphologic spectrum, especially within the category of leiomyomas, is responsible for diagnostic problems more frequently with leiomyosarcoma (including mitotically active, apoplectic, and leiomyoma with bizarre nuclei) but also with endometrial stromal tumors. In the former scenario, clinical information, gross appearance as well as strict utilization of morphologic criteria including cytologic atypia, mitotic activity, and tumor cell necrosis are clues in establishing the correct diagnosis. It is important to keep in mind that mitotic rate thresholds vary for the different subtypes of leiomyosarcoma. Of note, p16 should be used with caution in supporting a diagnosis of leiomyosarcoma as it is often positive in leiomyomas with bizarre nuclei and leiomyomas with apoplectic change (in the latter most frequently and more intense near areas of necrosis). MED12 mutations have also a very limited role in this differential diagnosis. Endometrial stromal tumors are by far, less common than smooth muscle tumors, but can be confused with leiomyosarcomas if they are associated with an undifferentiated uterine sarcoma and the low-grade component is overlooked or they have a myxoid/fibroblastic morphology. The differential diagnosis may be confounded if the latter is associated with a high-grade endometrial stromal sarcoma. It is important to highlight that CD10 is not a reliable marker in these differentials and should be used as a part of a panel of antibodies that also includes desmin and h-caldesmon. Two other recently categorized tumors in the uterus that merit special mention are PEComa and inflammatory myofibroblastic tumor as they enter in the differential diagnosis of smooth muscle tumors. PEComa may be part of the tuberous sclerosis syndrome and may show either a predominantly epithelioid or spindle morphology or combination thereof. Rarely, it may contain melanin pigment. There is variable positivity for HMB-45, MelanA, MiTF, and CathepsinK, and some tumors have been shown to express TFE-3 especially when associated with "clear cell" morphology. Patients with adverse outcome have tumors with $\geq 2$ of the following features: $\geq 5 \mathrm{~cm}$, infiltration, high-grade cytologic features, mitotic rate $\geq 1 / 50$ high-power fields, necrosis, or lymphovascular invasion. Inflammatory myofibroblastic tumor is important to recognize as it often mimics myxoid smooth muscle tumors, either benign or malignant. The presence of an associated lymphoplasmacytic infiltrate should alert to that possibility and ALK studies (immunostain or FISH) are helpful in establishing this diagnosis. These tumors can behave in a malignant manner if large, associated with abundant myxoid change, brisk mitotic rate or show tumor cell necrosis. Modern Pathology (2016) 29, S104-S120; doi:10.1038/modpathol.2015.139
\end{abstract}

Smooth muscle tumors represent the most common uterine mesenchymal neoplasms that may cause diagnostic dilemmas for the practicing surgical pathologist.

Benign uterine smooth muscle tumors, especially leiomyoma variants, display a wide spectrum of

Correspondence: Dr E Oliva, MD, Department of Pathology, Massachusetts General Hospital, 55 Fruit Street, Boston, MA 02114, USA.

E-mail: eoliva@mgh.harvard.edu

Received 30 September 2015; revised 8 October 2015; accepted 26 October 2015 gross and morphologic appearances often causing concern for malignancy and thus are a common source of diagnostic problems. Correct classification is important as currently prognosis of its malignant counterpart, leiomyosarcoma, is dismal even when confined to the uterus at time of diagnosis. ${ }^{1-3}$ Interestingly, the recent AJCC staging system of soft tissue sarcomas has been recommended to stage uterine malignant smooth muscle tumors. However, it is important to note that several studies have shown no advantage of this system over the old FIGO staging system to improve prediction of overall survival in patients with leiomyosarcoma, ${ }^{4-7}$ 
whereas neither system is ideal in classifying patients into four clinically significant stages. Furthermore, criteria for malignancy used in the classification of smooth muscle tumors in soft tissues differs significantly from those used in the uterus, likely related to the influence of the hormonal milieu in the female genital tract. For example, progestins are known to be associated with increased mitotic activity, infarction, and other morphologic changes in smooth muscle tumors that may lead to the incorrect diagnosis. Thus, inquiring about the clinical history, especially about progestin intake may be very helpful in the correct interpretation of a uterine smooth muscle tumor. A third system has been developed focusing on patient 5-year outcome based on specific parameters that include age at diagnosis, tumor size, histologic grade, mitotic index, cervical involvement, extrauterine spread, and distant metastases, ${ }^{8,9}$ which appears to have been validated using external cohorts. ${ }^{10}$ As immunohistochemistry (mostly p16 and p53), and molecular tools including MED12 mutations have currently a very limited role in the classification of smooth muscle tumors as benign or malignant, morphologic examination remains the cornerstone in the diagnosis of these tumors. ${ }^{11}$

Uterine leiomyosarcoma, the most frequent uterine sarcoma, is seen as a large solitary mass (average $10 \mathrm{~cm}$ ) or within a "fibroid" uterus. On sectioning, it displays a fleshy variegated cut surface with common hemorrhage and/or necrosis. When epithelioid, the consistency can be softer and if myxoid it may have a gelatinous, "sticky" cut surface. An infiltrative growth into the myometrium is often noted grossly or under the microscope, but some leiomyosarcomas may be relatively well circumscribed. The gross appearance of the smooth muscle tumor is frequently overlooked but it is often helpful either at the time of frozen section or during the final evaluation of the tumor.

Leiomyosarcomas are divided into spindled, epithelioid and myxoid, but variable admixtures thereof are not uncommon. Most spindled and epithelioid leiomyosarcomas are hypercellular but they can be normo- or hypocellular, the latter being more common in the myxoid variant where cells are embedded in an abundant weakly basophilic matrix, strongly positive with Alcian blue and colloidal iron. Spindle cell leiomyosarcoma shows long compact intersecting fascicles of fusiform cells with eosinophilic cytoplasm and elongated "blunt-ended" nuclei. The neoplastic cells in myxoid leiomyosarcoma have scant cytoplasm and oval, spindle, or stellate nuclei that may or not be arranged in loose fascicles, whereas epithelioid neoplasms are composed of sheets, nests, or cords of cells with abundant typically eosinophilic cytoplasm, although clear cells may be present and rarely predominate. ${ }^{12}$ To establish a diagnosis of myxoid leiomyosarcoma, studies have used variable thresholds ranging from 30 to $60 \%$. In general $>50 \%$ component of myxoid or epithelioid component is desired to render a diagnosis of either myxoid or epithelioid leiomyosarcoma although minor components should be noted in the pathology report as it may be the only morphology present in metastases. ${ }^{13-20}$

In general, to render a diagnosis of malignancy in smooth muscle tumors of the uterus is relatively straightforward as leiomyosarcomas usually display marked nuclear atypia, high mitotic rate, and tumor cell necrosis. However, it is important to keep in mind that the diagnostic threshold for mitotic rate differs for the different leiomyosarcoma variants.

To establish a diagnosis of spindle cell leiomyosarcoma a combination of two of three of the following features are needed: tumor cells necrosis, marked moderate to severe cytologic atypia and/or $\geq 10$ mitoses/10 high-power fields (HPFs). An epithelioid leiomyosarcoma should show $\geq 4$ mitoses/10 HPFs with either tumor cell necrosis or at least moderate cytologic atypia, whereas a myxoid leiomyosarcoma can be diagnosed with the finding of either tumor cell necrosis or marked cytologic atypia; in their absence, $\geq 2$ mitoses/10 HPFs is diagnostic of malignancy. Notice that the threshold to establish a diagnosis of myxoid leiomyosarcoma is much lower than hat used for the spindle cell variant, thus, it is important to sample extensively any smooth muscle tumor particularly if myxoid in order to identify the most mitotically active areas. Furthermore, sampling may show an infiltrative growth, lymphovascular invasion, or presence of conventional and/or epithelioid components, which will facilitate the diagnosis of malignancy.

\section{Morphologic Evaluation of Diagnostic Criteria}

\section{Mitotic activity}

Even though mitotic index is important in establishing the diagnosis of leiomyosarcoma, this finding in isolation is not enough to render such diagnosis as some leiomyoma variants may occasionally have brisk mitotic activity. As mentioned above, a cutoff of $10, \geq 4$, and $\geq 2$ mitoses/10 HPFs is used for spindle (Figure 1), epithelioid or myxoid leiomyosarcomas, respectively. ${ }^{12}$ Thus, objective mitotic count is crucial but at the same time it is often difficult to be certain about it as apoptotic cells with karyorrhectic nuclei can be easily misinterpreted as mitoses. Karyorrhectic nuclei/apoptotic cells often have dense "pink" retractile cytoplasm and coarse/ granular chromatin in contrast to delicate appearance of the chromatin associated with a pale cytoplasm and absence of nuclear membranes seen in true mitoses. ${ }^{18}$ When scrutinizing a smooth muscle tumor for mitotic activity and considering "atypical mitoses" in the absence of typical ones should alert to the possibility of being confronted with apoptotic cells. Ki-67 is often performed to aid in the differential diagnosis between leiomyoma 


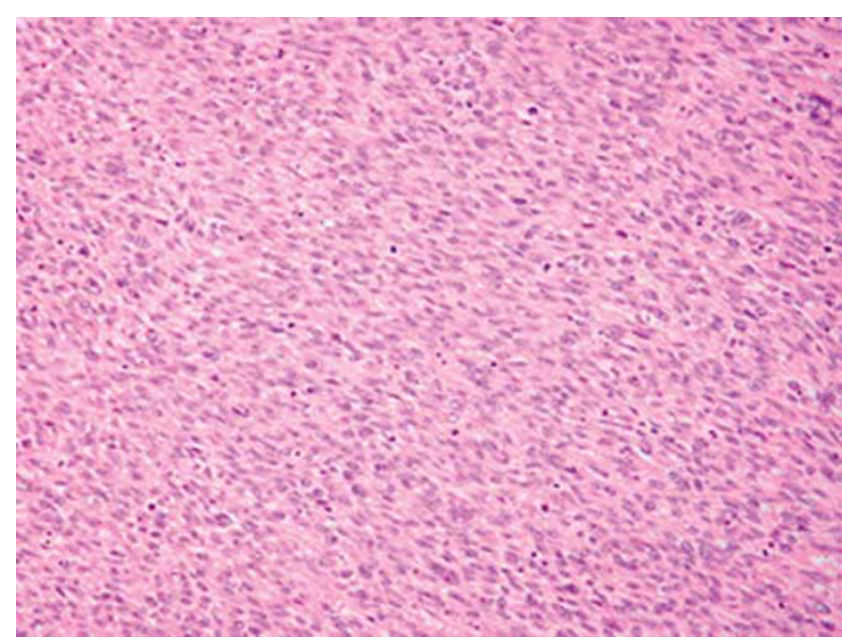

Figure 1 Spindle cell leiomyosarcoma. Although no striking cytologic atypia is noted at low power, there is brisk mitotic activity. This tumor may be diagnosed by some as low-grade leiomyosarcoma.

variants and leiomyosarcoma, but is infrequently helpful as typically overestimates mitotic index and furthermore, results show extensive overlap between the most problematic leiomyoma variants and leiomyosarcoma. PHH3 may be more helpful than Ki-67 when it is difficult to be certain about mitotic rate based on routine examination, and it may be particularly useful in leiomyomas with bizarre nuclei, although still not completely reliable. ${ }^{21}$

\section{Nuclear atypia}

Evaluation of cytologic atypia is subjective and may vary greatly among pathologists; thus, it is important to keep in mind the following: (1) evaluate atypia at medium power magnification $(\times 10)$; $(2)$ compare cytologic features of tumor with surrounding myometrium if possible; and (3) look for background nuclear atypia not atypia of "bizarre" type that often is confined to groups of cells in an otherwise banal appearing leiomyoma. Cytologic atypia often includes more than one of the following features; (a) high nuclear size (high nuclear to cytoplasmic ratio); (b) irregular nuclear membranes; (c) nuclear pleomorphism; (d) hyperchromatism; and (d) prominent nucleoli or more than one nucleoli. ${ }^{18,22}$

There are several grading systems that could be applied to uterine leiomyosarcomas as they are used in soft tissues including the Broders system (grade 1 -mild cytologic atypia; grade 2-more nuclear irregularity, grade 3-between grade 2 and 4, grade 4 -presence of bizarre cells) ${ }^{23}$ and the French classification (FNCLCC) that divides soft tissues sarcomas into three categories based on tumor cell necrosis, mitoses, and degree of differentiation. ${ }^{24,25}$ However, all of these systems fail in identifying bona fide low-grade leiomyosarcomas. On the basis of the Stanford criteria for malignancy in smooth muscle tumors, the vast majority of leiomyosarcomas are also by definition high grade. ${ }^{22}$ In one recent study, tumors initially diagnosed as low-grade leiomyosarcoma were proved to be a heterogeneous group of tumors that comprised atypical smooth muscle tumors as well as other mesenchymal neoplasms including endometrial stromal sarcomas with smooth muscle differentiation. Other tumors within that category that were diagnosed as low grade were histologically indistinguishable from conventional leiomyosarcomas aside from having a lower prevalence of tumor cell necrosis. ${ }^{26}$ Despite the infrequency of the latter feature, patient outcome was basically identical to that of high-grade tumors. Thus, even though low-grade leiomyosarcomas exist, they are rare and criteria to recognize this subset of tumors is currently lacking.

\section{Tumor cell necrosis}

Three types of necrosis can be encountered in smooth muscle tumors: (1) Ulceration with underlying necrosis if submucosal; (2) infarct-type necrosis in benign and malignant neoplasms; and (3) tumor cell necrosis (Figure 2a and b), which is only seen in leiomyosarcomas. The latter is defined by an abrupt transition from necrotic to non-necrotic areas without interposed granulation tissue. Viable tumor cells typically have a perivascular distribution. Most importantly in both necrotic and preserved areas, marked cytologic atypia is noticeable, usually without associated inflammation. ${ }^{22}$ However, interobserver agreement in the interpretation of tumor cell necrosis is inconsistent and it was only fair even among experienced gynecologic pathologists in one recent study. ${ }^{27}$ Another study showed that tumor cell necrosis was present in about one third of leiomyosarcomas studied (26 out of 72 ) and all but one with tumor cell necrosis (44 spindle, 22 epithelioid, 6 myxoid), also showed marked cytologic atypia as well as $\geq 10$ mitoses/10 HPFs. ${ }^{28}$ These studies highlight the importance of evaluating both cytologic atypia and mitotic activity, as most leiomyosarcomas show these features. Many leiomyosarcomas also have infarct-type necrosis, the latter being more common than tumor cell necrosis. In contrast to the latter, infarct-type necrosis is characterized by finding granulation tissue or hyalinization between necrotic and non-necrotic areas, frequently associated with recent or old hemorrhage. The necrotic areas have a mummified appearance and both tumor and vessels appear dead. However, it is important to keep in mind that (a) when infarcttype necrosis is seen at a very early stage, typical features are absent, and (b) infarct-type necrosis may be superimposed to tumor cell necrosis, both making the distinction from tumor cell necrosis difficult which underscores evaluation of "early" non 

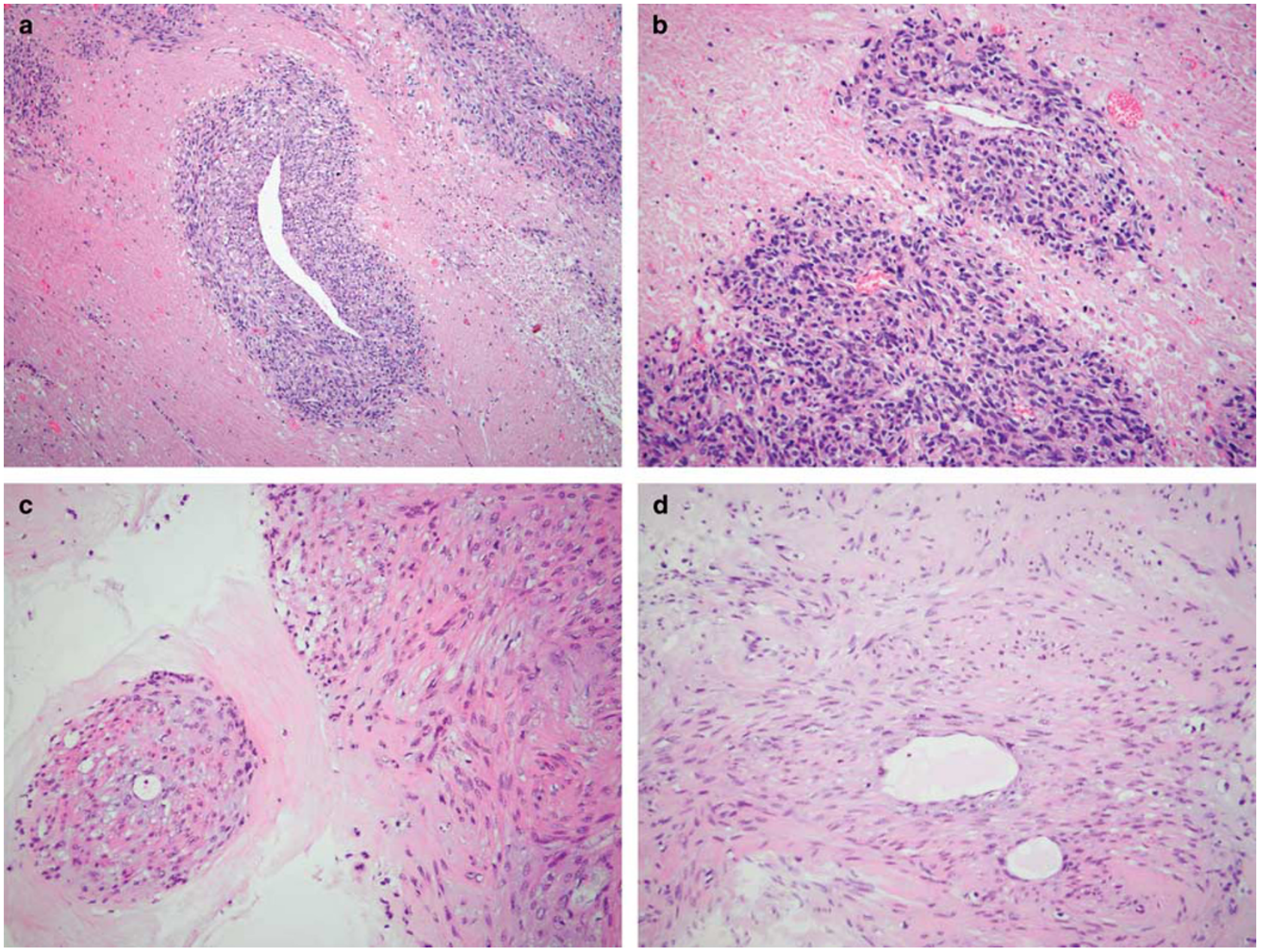

Figure 2 Spindle cell leiomyosarcoma. Perivascular tumor cell necrosis is associated with prominent cytologic atypia and atypical ghost cells (a and b). Leiomyoma. Infarct-type necrosis imparts a similar low-power appearance (c); however, no cytologic atypia is noted. The background appears devoided of atypical cells (d).

well-characterized necrosis to be made in conjunction with nuclear atypia and mitotic activity (Figure 2c and d).

As mentioned earlier, it is most important not to confuse leiomyoma variants with the different subtypes of leiomyosarcoma. Within the category of spindle leiomyosarcoma the most common variants in this differential diagnosis include: apoplectic leiomyoma, leiomyoma with bizarre nuclei and mitotically active leiomyoma. Other tumors that may enter in this differential diagnosis although by far much less common are spindle rhabdomyosarcoma and undifferentiated uterine sarcoma.

Leiomyomas with bizarre nuclei (Symplastic leiomyoma) (Figure 3a) ${ }^{12}$ often cause concern for malignancy as display large atypical multinucleated or mononucleated cells that may have an extensive/ diffuse distribution within the tumor or may show high density in some areas, nuclei display prominent nucleoli as well as karyorrhectic nuclei with coarse chromatin simulating abnormal mitoses (Figure 3b), and focal increased mitotic activity (up to 8/10 HPFs) may be noted. ${ }^{29-31}$ On the other hand, it is well known that some leiomyosarcomas have multinucleated cells similar to those found in leiomyomas with bizarre nuclei as well as "leiomyoma-like" areas increasing confusion between these two entities. ${ }^{32}$ Finally, it has been shown that leiomyomas with bizarre nuclei are commonly p16 and p53 positive (Figure 3c and d) as reported in leiomyosarcomas. Thus, although has been emphasized the usefulness of p53 and p16 in the distinction between leiomyoma and leiomyosarcoma, ${ }^{31,33-36}$ these markers should not be used when confronted with this differential diagnosis, except if wild-type p53 expression and negative p16 that support a diagnosis of leiomyoma with bizarre nuclei. Ki67 also shows a remarkable degree of overlap between leiomyoma with bizarre nuclei and leiomyosarcoma, and thus, it is not helpful in most instances. ${ }^{34,37-39}$ Yet, other cell cycle regulatory markers including p21 and p27 appear to show extensive overlap between these two categories of smooth muscle tumors. ${ }^{31}$ MED12 mutations that are common in typical leiomyomas ${ }^{40-43}$ are uncommon in leiomyomas with bizarre nuclei but also rare in leiomyosarcomas. ${ }^{44-46}$ 

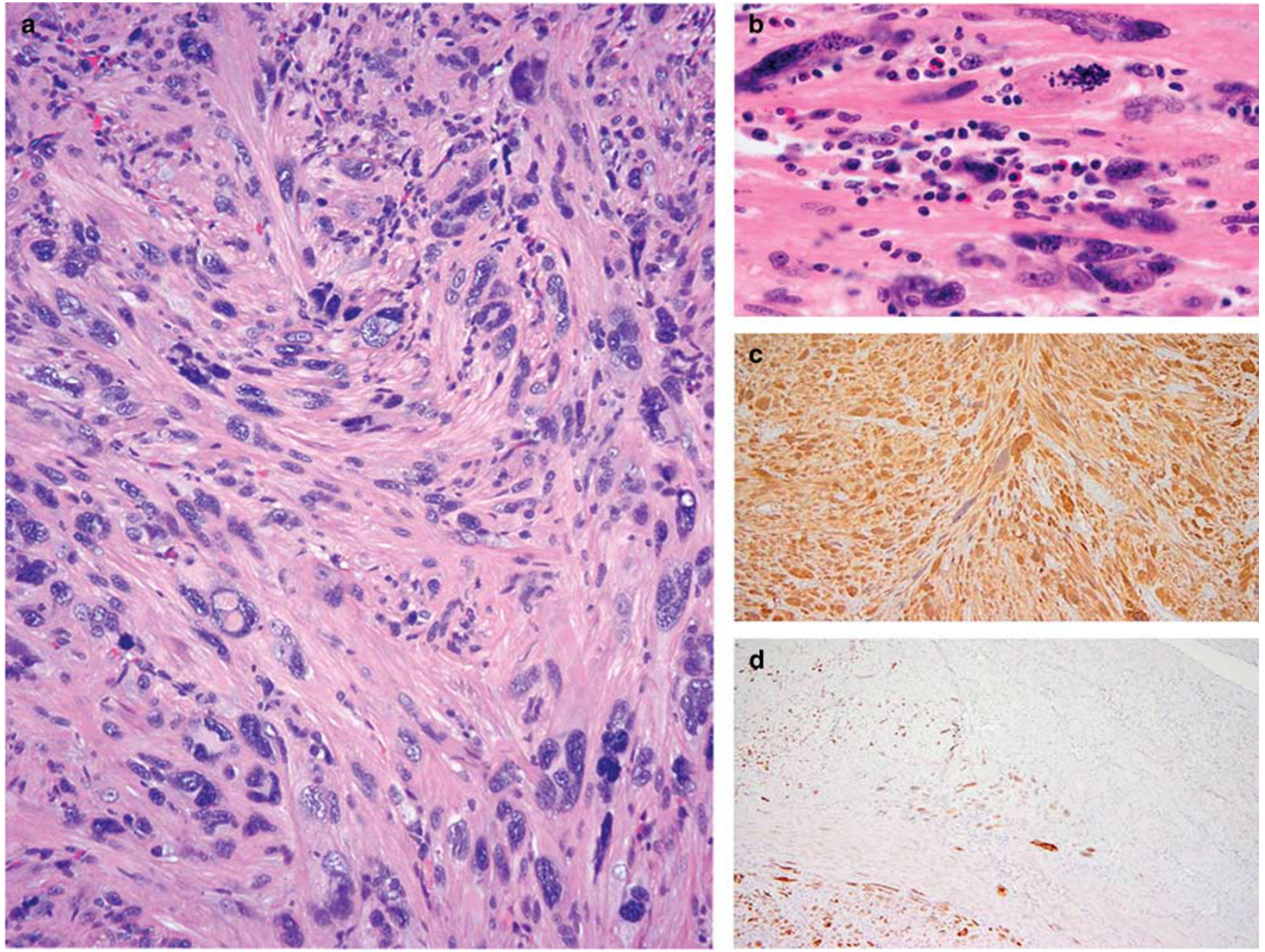

Figure 3 Leiomyoma with bizarre nuclei. There is diffuse distribution of bizarre nuclei (a); karyorrhectic nucleus mimics an atypical mitosis (b), both features may cause concern for malignancy. Diffuse possitivity for p16 (c) and p53 (d) of the bizarre tumor cells is seen.

It is important to establish the correct diagnosis as often patients with leiomyomas with bizarre nuclei are in their reproductive age and the initial treatment may only be myomectomy. ${ }^{29-31}$ Helpful features to establish the diagnosis of leiomyoma with bizarre nuclei include a patchy distribution of the "atypical" cells in most tumors, prominent nuclear pseudoinclusions, and degenerative-type atypia with pyknotic nuclei. Average mitotic count is typically $1-2 / 10$ HPFs, although isolated counts up to 7-8 mitoses/10 HPFs may be noted. It is very important to recognize that areas not containing bizarre cells (background smooth muscle cells) show bland cytologic features. It is also important not to confuse karyorrhectic nuclei with atypical mitoses in the absence of typical ones. Other helpful associated features include the finding of cells with rhabdoid morphology. In these tumors, there are often associated vascular changes that include fibrinoid necrosis of vessels wall as well as vessel lumen obliteration and perivascular inflammatory infiltrate. ${ }^{29}$ Tumor cell necrosis is not seen. Compiled experience with these tumors has shown that they are benign even when they are associated with diffuse distribution of the bizarre nuclei. ${ }^{29-31}$
Recently, it has been shown that some leiomyomas that contain bizarre nuclei may be associated with the leiomyomatosis-renal cell carcinoma syndrome, in which patients develop uterine and cutaneous leiomyomas and papillary renal cell carcinoma. The syndrome has an autosomal dominant inheritance with alteration of fumarate hydratase $(F H)$ gene located in the long arm of chromosome $1 .{ }^{47}$ These leiomyomas are characterized by prominent eosinophilic macronucleoli with a perinucleolar halo, the presence of bizarre nuclei, as well as a fascicular growth of spindle cells with increased cellularity, staghorn-type vessels, fibrillary cytoplasm, rhabdoid-like inclusions, and alveolar-type edema (Figure $4 \mathrm{a}-\mathrm{C}$ ). ${ }^{48-50}$ However, these features are not easily reproducible and it has been shown that leiomyomas with bizarre nuclei that are not associated with this syndrome can also show absence of staining for FH (Figure 4d) with positive S2C in the same cells, indicating that the above morphologic features are not diagnostic of this syndrome. ${ }^{48,51}$ Thus, absence of staining should be used as a "triage" for further genetic testing but not as a diagnostic tool in this scenario. 

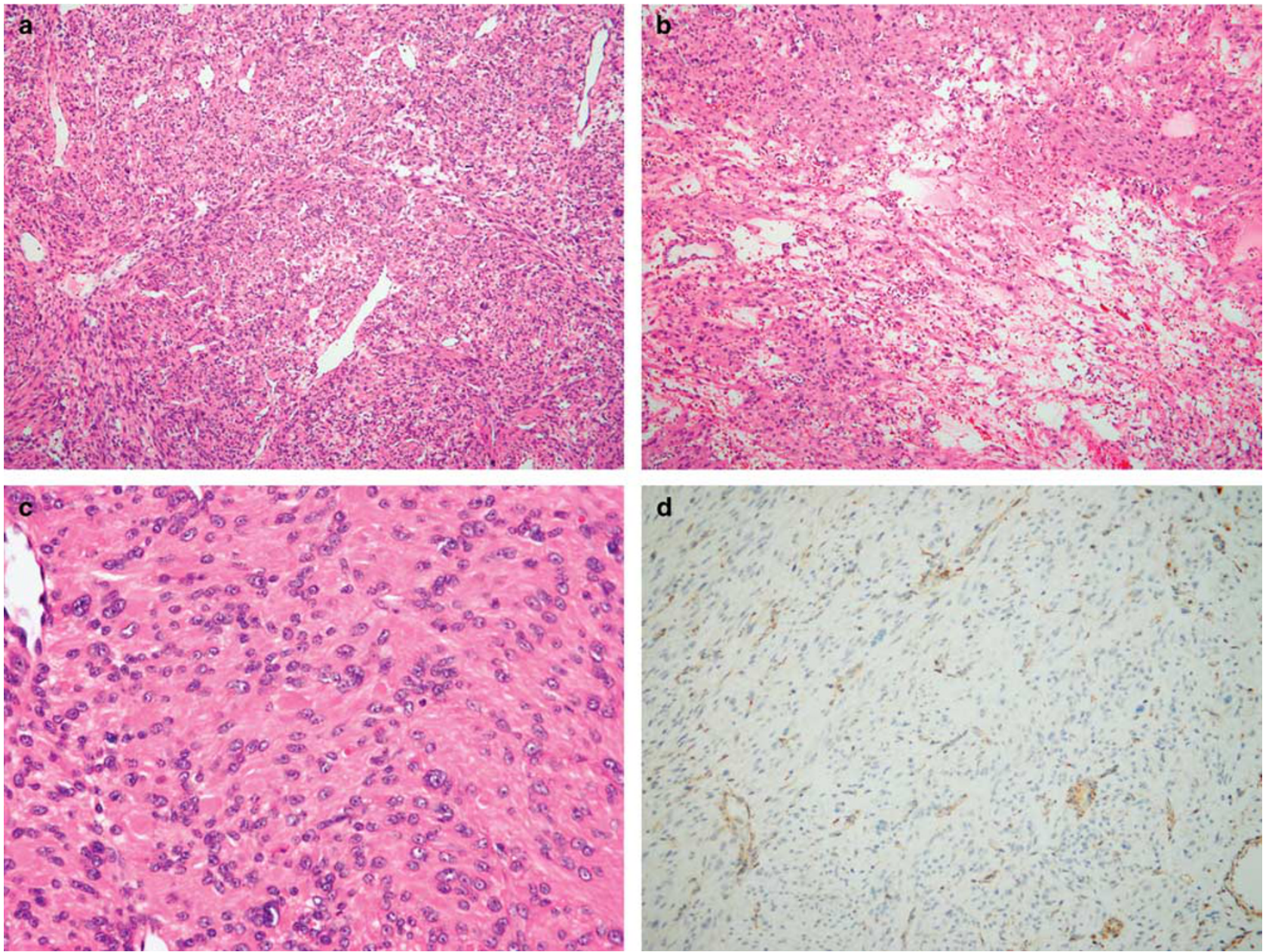

Figure 4 Leiomyoma with bizarre nuclei associated with loss of fumarate hydratase (FH). Hemangioperytoma-like vessels (a) and "alveolar-type" edema (b) are noted. Cells are associated with fibrillary cytoplasm and large nucleoli surrounded by pale halo (c), and show loss of FH expression (d).

Finally, avoid using the term atypical leiomyoma for a leiomyoma with bizarre nuclei/symplastic leiomyoma as this term is used in the most recent WHO classification as a synonym of smooth muscle tumor of uncertain/low malignant potential. ${ }^{12}$

Mitotically active leiomyoma has as concerning morphologic feature its increased mitotic activity, especially when $>5$ mitoses/10 HPFs are noted. Some tumors may have up to $10-15$ mitoses. It is important to note that mitoses should not be sought near areas of ulceration or infarction where are typically increased. These tumors lack any degree of cytologic atypia, which is the most important diagnostic feature to establish a benign diagnosis. Thus, sampling is important especially of any grossly non-typical areas to rule out a leiomyosarcoma. Tumor cell necrosis should be absent. In contrast to leiomyosarcomas, these tumors almost always occur in women of reproductive age and are associated with the secretory phase of the menstrual cycle, pregnancy, or the use of exogenous hormones, consistent with the effect of progestins on uterine leiomyomas. ${ }^{52,53}$ Tumors with $>15$ mitoses/10 HPFs may be clinically benign, but as experience is exceedingly limited they may be better classified as "leiomyoma with increased mitotic activity, but experience limited" or "smooth muscle tumor of uncertain/low malignant potential/atypical leiomyoma" advising close follow-up. ${ }^{12}$

Apoplectic leiomyoma is also designated as hemorrhagic cellular leiomyoma, as this term appropriately emphasizes the multifocal nature of the hemorrhagic foci on gross and microscopic examination. On gross examination, these multiple hemorrhagic areas may be accompanied by cystic change and typically show a stellate contour on microscopic scrutiny (Figure $5 \mathrm{a}$ and b). In the surrounding hypercellular areas, the cells appear "plumper" or slightly pseudoepithelioid with enlarged nuclei, nucleoli, and often visible mitotic activity (up to $8-9 / 10$ HPFs) but average mitotic count is $<2 / 10$ HPFs (Figure 5c). ${ }^{38,54}$ These hypercellular areas often cause concern for malignancy, especially when multiple foci are close together imparting a "busy" appearance. Another confounding feature is the presence of associated myxoid 

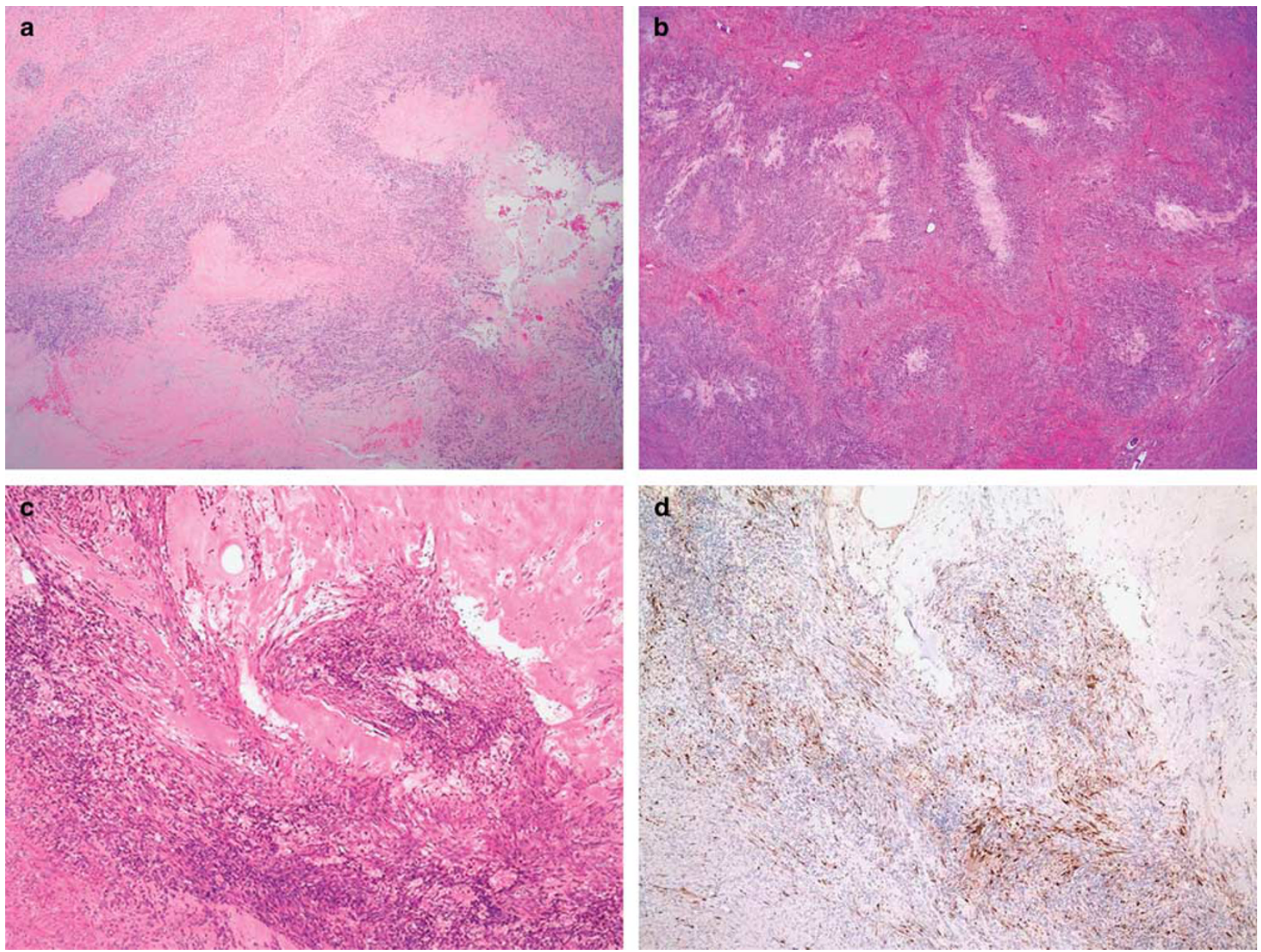

Figure 5 Leiomyoma with apoplectic change. The tumor shows irregular outlines associated with individual foci of necrosis and surrounding areas of hypercellularity often causing concern for malignancy (a and $\mathbf{b}$ ). Transition from hyper- to normocellular areas (as typically seen in conventional leiomyomas) is noted and it is a helpful clue (b). p16 positivity is seen in hypercellular areas close to infarct (c and d).

change in these areas. Keep in mind that these hypercellular areas typically show increased Ki-67 expression and not infrequently display p16 positivity, which can be relatively striking (Figure $5 \mathrm{~d}$ ). ${ }^{55}$ As the lesion evolves, there also may be myxoid degeneration of the hemorrhagic focus itself as well as bands of hyalinization of the surrounding cellular smooth muscle. If the affected smooth muscle area has not yet become overtly hemorrhagic, one can often notice at low power a vague nodular configuration of hypercellular smooth muscle with scattered erythrocytes as well as single or groups of apoptotic cells, which often also have a pseudoepithelioid morphology and are associated with hyperchromatic nuclei that cause concern for tumor cell necrosis. ${ }^{18}$ There are two important clues to the diagnosis of apoplectic leiomyoma: (1) low-power appearance, where a "zonation" phenomenon may be appreciated moving away from the hemorrhagic focus and the cellularity and cytologic features in the latter areas are those of a conventional leiomyoma, and (2) history of contraceptive intake. As this leiomyoma variant typically occurs in reproductive-age women either taking oral contraceptives or who are pregnant/postpartum, it is crucial to inquire about that possibility as this history may help to point towards the correct diagnosis. ${ }^{18}$

Highly cellular leiomyoma. Increased cellularity in a smooth muscle tumor potentially may cause concern for malignancy. This feature was used in the past as an important criterion in the diagnosis of leiomyosarcoma, but is currently well established that benign smooth muscle tumors may be highly cellular in the absence of cytologic atypia, brisk mitotic activity, and tumor cell necrosis. ${ }^{56}$ However, it is important to keep in mind that any given combination(s) of leiomyoma variants can occur, thus a cellular or highly cellular leiomyoma may be associated with increased mitotic activity and in such case the tumor would be designated as a mitotically active cellular/highly cellular leiomyoma. As mentioned earlier, no cytologic atypia or tumor 
cell necrosis should be noted and thus it is important to sample extensively these tumors.

Undifferentiated endometrial/uterine sarcoma and spindle cell rhabdomyosarcoma should be considered in the differential diagnosis of a spindle leiomyosarcoma. Although the former is a diagnosis of exclusion, ${ }^{57,12}$ its distinction from a leiomyosarcoma may be very difficult either because the leiomyosarcoma is poorly differentiated or it is associated with dedifferentiation (dedifferentiated leiomyosarcoma). ${ }^{58}$ However, the latter will display, in most cases, a discrete transition from betterdifferentiated to high-grade pleomorphic areas lacking smooth muscle differentiation. These dedifferentiated areas do not express muscle markers increasing the degree of confusion. Thus, sampling may be important to identify the differentiated areas, although prognosis is dismal in all patients. Spindle cell rhabdomyosarcoma shows cells with bright eosinophilic cytoplasm, which at least should alert one to search for cross striations and perform immunohistochemical stains for skeletal markers. Of note, as rhabdomyosarcomas are also positive for desmin, this antibody alone should not be used in this differential diagnosis. ${ }^{59}$

Within the category of myxoid leiomyosarcoma the main differential diagnosis includes hydropic change within a leiomyoma and much less frequently myxoid leiomyoma, intravenous leiomyomatosis with myxoid/hydropic change, myxoid variant of endometrial stromal sarcoma, or even rarely inflammatory myofibroblastic tumor or myxoid change within the myometrium (associated with lupus erythematosus or neurofibromatosis).

Leiomyoma with hydropic change (hydropic leiomyoma). Clinically, especially intraoperatively, a fast-growing smooth muscle tumor is often suspected by the surgeon to be a leiomyosarcoma. When opening the uterus, the tumor may have an unusual multinodular or poorly demarcated appearance and may exude fluid, which is not infrequently suspected by the pathologist to be "myxoid" in nature. It is important to keep in mind that myxoid matrix, if striking, imparts a sticky "touch" to the cut surface, but it does not typically exudes watery fluid, especially if "squeezed", an important gross difference. ${ }^{60}$ On microscopic examination, hydropic (edema) change may be confused with myxoid matrix, more so if the hydropic change extends beyond the confines of the leiomyoma mimicking an infiltrative growth and if obliterates the usual tumor architecture. ${ }^{61}$ However, the overall appearance of a leiomyoma with hydropic change differs from that seen in a smooth muscle tumor with myxoid change. Typically, the hydropic change is often accompanied by numerous thick-walled blood vessels and only threads, cords, or trabeculae of smooth muscle cells may be seen although complete "dropout" of cells may occur, which contrast with myxoid tumors, where free floating stellate or spindle cells are seen within the intervening myxoid matrix. Hydropic areas may alternate with hyalinized areas, and no cytologic atypia and only rare mitoses are noted in leiomyomas with hydropic change. Although watery fluid is typically pale eosinophilic and myxoid matrix tends to be basophilic, Alcian blue or colloidal iron are helpful in this distinction as they are typically negative in leiomyomas with hydropic change. ${ }^{61}$

Myxoid leiomyoma is even rarer that myxoid leiomyosarcoma and this diagnosis should only be made in tumors that are small (essentially $<5 \mathrm{~cm}$ ), completely well circumscribed, with no cytologic atypia and minimal to absent mitotic activity $(<2 / 10$ HPFs) after extensive sampling (Figures 6a-d). ${ }^{13-15,19,62}$ It is important to be aware that a benign smooth muscle tumor may be only partially myxoid, and that if the non-myxoid areas are misconstrued as myometrium, the tumor may be interpreted as having infiltrative margins and likely to be a myxoid leiomyosarcoma. Myxoid change may occur in leiomyomas in pregnant women and also near areas of infarction. ${ }^{54,63}$ Distinction between a benign and malignant myxoid smooth muscle tumor may be difficult in curettage specimens and the pathologist should be very cautious in this scenario. When confronted with a frozen section/or curettage of a myxoid proliferation without obvious features of malignancy, it is best to indicate the myxoid nature of the tumor to the surgeon and defer the final interpretation after extensive sampling has been performed. Intravenous leiomyomatosis may be rarely associated with prominent myxoid change, an appearance that occasionally can be prominent in leiomyosarcoma. ${ }^{64,65}$ The finding of any degree of cytologic atypia or mitotic activity should favor the diagnosis of leiomyosarcoma.

Myxoid endometrial stromal sarcoma comprises a subset of endometrial stromal sarcomas with prominent myxoid and/or fibroblastic background ${ }^{62,66,67}$ that are often confused with myxoid leiomyosarcoma (the latter more common). ${ }^{68}$ This differential diagnosis may be confounded by the fact that some low-grade endometrial stromal sarcomas are associated with a high-grade component (high-grade endometrial stromal sarcoma with $t(10,17)^{69}$ showing relatively small but epithelioid tumor cells forming nests that can be confused with an epithelioid smooth muscle component. Helpful features to establish the diagnosis of low-grade endometrial stromal sarcoma include; (a) typical tongue-like pattern of infiltration, (b) absence of fascicular growth, (c) arteriole-like vessels, (d) in most cases, areas of conventional endometrial stromal neoplasia, ${ }^{70}$ and (e) lack of positivity for h-caldesmon. ${ }^{71}$ In the highgrade areas, the tumor cells are small with very brisk mitotic activity and are associated with a prominent sinusoidal vasculature. Although CD10, ER, and PR are typically positive in low-grade endometrial stromal sarcomas, it is important to keep in mind that the high-grade component is typically negative for these markers (but diffusely positive for cyclin 

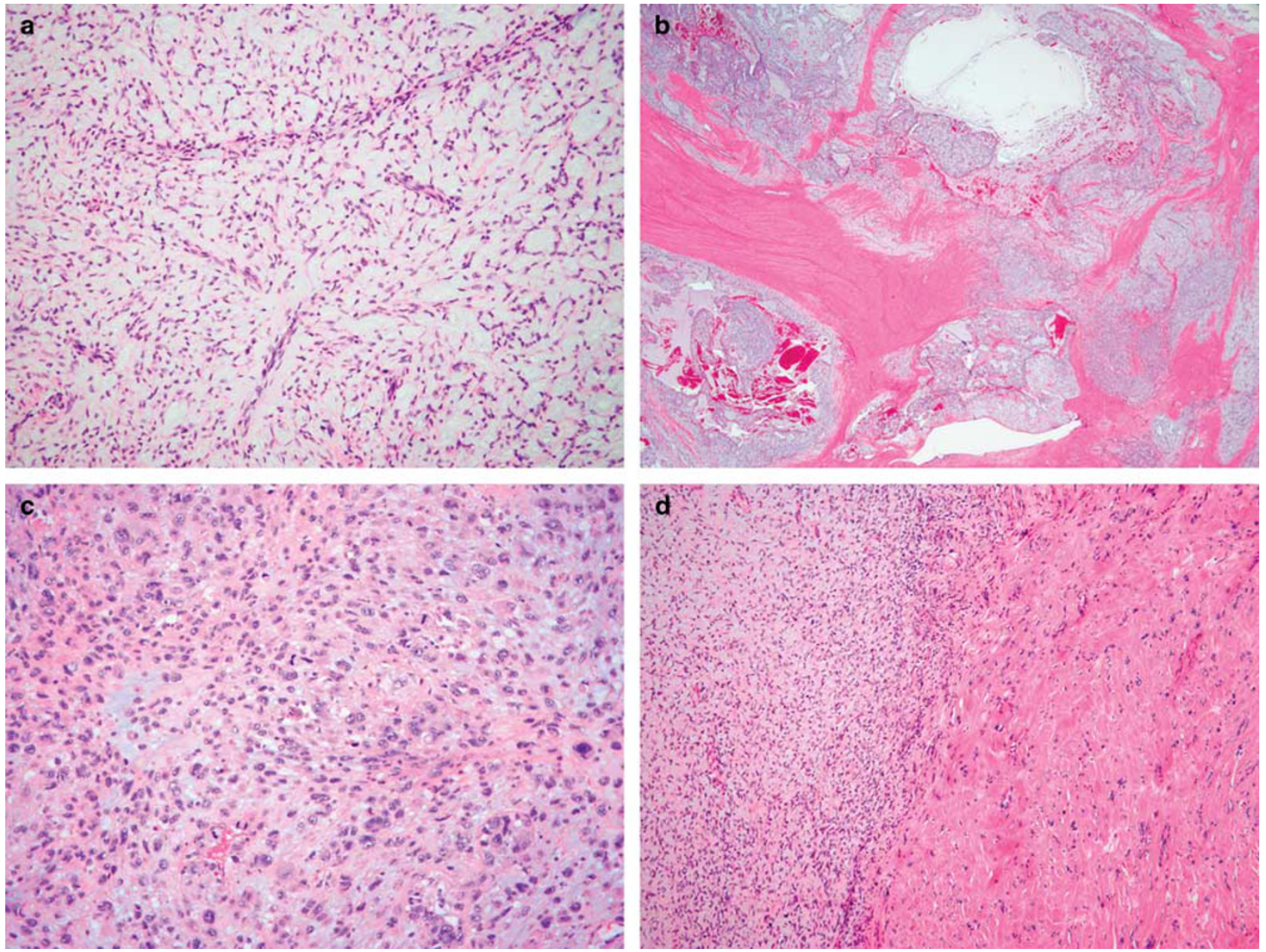

Figure 6 Myxoid smooth muscle tumors. A myxoid leiomyoma shows no cytologic atypia, mitoses or tumor cell necrosis (a). Myxoid leiomyosarcoma displays destructive myometrial invasion (b); cytologic atypia is common but not always present in malignant myxoid smooth muscle tumors (c); leiomyoma-like areas in a myxoid leiomysarcoma are noted (d).

D1 $)^{72}$ and that very commonly leiomyosarcomas express CD10 as well as ER and PR. ${ }^{73-78}$ Thus, when using immunohistochemistry, a panel rather than a single marker that includes desmin and h-caldesmon is necessary. Of note, myxoid smooth muscle tumors may show less expression of smooth muscle markers when compared to other leiomyosarcoma subtypes.

Inflammatory myofibroblastic tumor (Figure 7a and b) has a variably myxoid stroma and may present as a bulky myometrial mass with focally irregular borders that infiltrates surrounding tissues including parametrium and cervical stroma, not uncommonly having a gelatinous cut surface. These tumors often show mitotic activity, necrosis, and positivity for muscle markers. All these features raise as initial working diagnosis myxoid leiomyosarcoma. On microscopic examination, tumors grow in three main patterns: hypocellular/myxoid, fascicular, and less commonly hyalinized, patterns that can also be observed in leiomyosarcomas. Helpful morphologic features include: (1) usually striking lymphoplasmacytic infiltrate; (2) tissue culture-like appearance; (3) minimal cytologic atypia; (4) cells with a "ganglion-like" morphology; and (5) ALK cytoplasmic immunopositivity that tends to be stronger if the myofibroblastic tumor is predominantly myxoid. ${ }^{79-81}$ ALK gene rearrangements have been recently reported (Figure $7 \mathrm{c}$ ). ${ }^{80}$ The latter is helpful as no ALK expression has been identified in uterine smooth muscle tumors or endometrial stromal sarcomas up to date. These tumors can behave in a malignant manner if large, associated with abundant myxoid change, brisk mitotic rate, or tumor cell necrosis. ${ }^{80}$

Rarely, myxoid change can occur in the myometrium in patients with lupus erythematosus (with secondary muscle hypertrophy, termed as "myxoidosis") $^{82}$ or neurofibromatosis, type $\mathrm{I}^{83}$ forming variably circumscribed nodules. This phenomenon may raise problems in the differential diagnosis with a "low-grade" myxoid smooth muscle tumor in a curettage/biopsy specimen but not in hysterectomy specimens. Knowledge of the clinical history and awareness of its diffuse distribution may be helpful. 

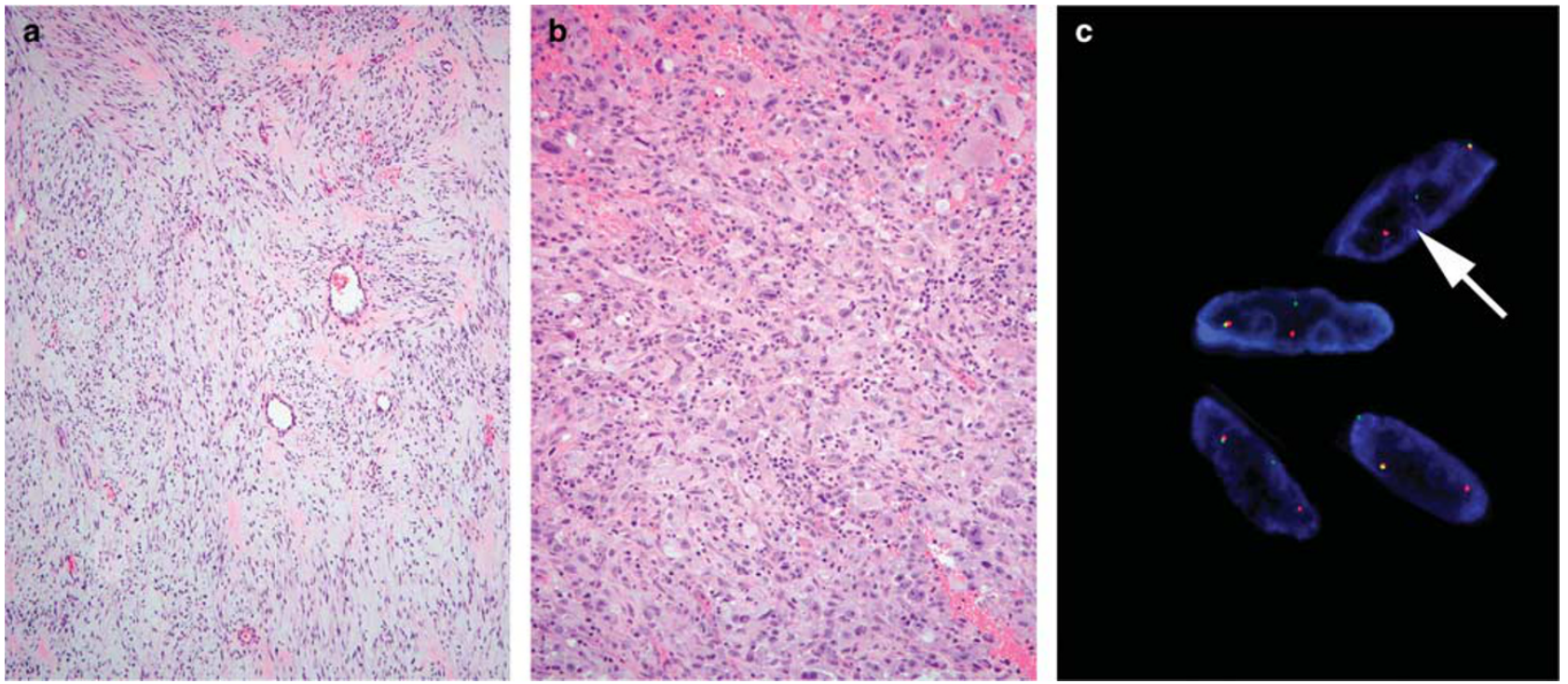

Figure 7 Inflammatory myofibroblastic tumor. Hypocellular, myxoid and spindle cell tumor with minimal cytologic atypia shows sprinkling of chronic inflammatory cells (a). Hypercellular tumor with epithelioid morphology is associated with prominent lymphocytes and plasma cells (b). ALK rearrangement is seen (split apart signal) confirming the diagnosis of inflammatory myofibroblastic tumor and excluding a smooth muscle tumor (c).

Epithelioid leiomyosarcomas have typically a broader differential diagnosis among uterine leiomyosarcomas as they have the most varied morphology including diffuse, nested, pseudoalveolar, corded, and trabecular growths or combination thereof. Before making a diagnosis of epithelioid smooth muscle tumor, a pseudoepithelioid appearance (Figure 8a) should be excluded as in fact it is more common than true epithelioid morphology and can be seen with: cross section of smooth muscle fascicles (Figure 8c), hydropic change often associated with hyalinization (Figure 8d), viable areas of smooth muscle neoplasia close to infarct-type necrosis, rhabdoid change, and leiomyomas from pregnant women. ${ }^{18}$ After excluding this pseudoepithelioid morphology, tumors in the differential diagnosis of epithelioid leiomyosarcoma include: PEComa, poorly differentiated carcinoma, uterine tumor resembling an ovarian sex-cord tumor, tumors derived from intermediate trophoblast, malignant melanoma (primary and metastatic) and less commonly other primary sarcomas including alveolar soft-part sarcoma, epithelioid angiosarcoma, epithelioid endometrial stromal sarcoma, pleomorphic rhabdomyosarcoma, or rhabdoid tumor. If the tumor is subserosal, the differential diagnosis may also include a gastrointestinal stromal tumor. Of note, leiomyosarcomas may be c-kit positive, ${ }^{75,84,85}$ but lack c-kit mutations and are negative for DOG1 (with rare exceptions) and CD34. ${ }^{86}$

PEComa belongs to the family of lesions that originate from the perivascular epithelioid cell (PEC). The PEC cell has abundant clear to eosinophilic granular cytoplasm (Figures 9a and b) and variably stains for melanocytic markers (HMB45, MelanA, MiTF, cathepsinK, and TFE3) (Figures 9c and d) with variable expression of smooth muscle markers. ${ }^{87-92} \mathrm{~A}$ strong association with lymphangiomyomatosis and tuberous sclerosis exists. ${ }^{88,90,91}$ PEComa may share with epithelioid leiomyosarcoma the following features: (1) infiltrative growth; (2) nested or diffuse growth; (3) spindle cell component; (4) hyalinization; (5) cells with abundant clear or eosinophilic cytoplasm and round to oval nuclei; and (6) common expression of smooth muscle markers. Features that favor an epithelioid smooth muscle tumor over a PEComa include: (a) diffuse cytoplasmic eosinophilia with no prominent granular quality; (b) spindle cell component with cells showing perinuclear vacuoles; (c) no delicate vasculature; (d) MelanA and TFE3 typically negative; (e) keratin and/or EMA (Figure 8b) often positive; (f) basal lamina and pinocytotic vesicles but no premelanosomes seen by electron microscopy. ${ }^{93-95}$ Features that favor PEComa over an epithelioid leiomyosarcoma include: (1) association with tuberous sclerosis; (2) coexistence of lymphangiomyomatosis in the uterus, lymph nodes, or other locations; (3) delicate sinusoidal vasculature (Figure 9a); (4) fibrillary quality of the cell cytoplasm; (5) multinucleated giant cells and 'spider'-like cells; (6) cells with glycogen or lipid-distended cytoplasm; (7) melanin pigment; (8) Melan A, MiTF, cathepsinK, and/or TFE3 expression; and (9) lack of expression of epithelial markers (keratin and EMA). Among melanocytic markers Melan A is most frequently expressed although expression of any of these markers (especially HMB45 and melanA) is often focal. ${ }^{89}$ PEComas with a predominant component of clear cells also show extensive TFE3 and cathepsinK positivity with variably HMB45 positivity and they are not typically associated with TSC mutations. ${ }^{96,97}$ 

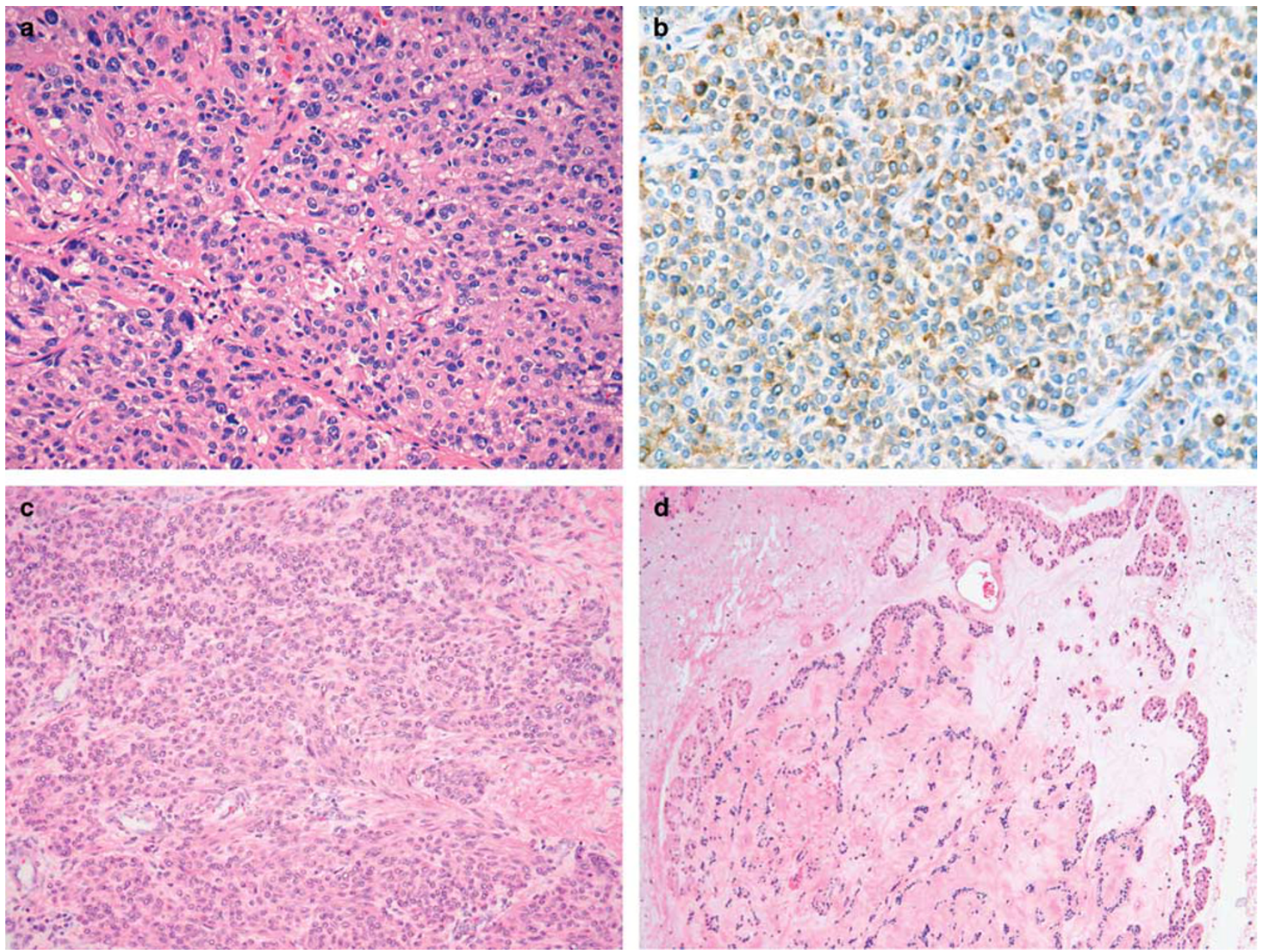

Figure 8 Epithelioid leiomyosarcoma. The tumor grows as tight nests of cells with abundant eosinophilic cytoplasm and prominent cytologic atypia (a); tumor cells stain for EMA (b). A pseudoepithelioid morphology may be imparted when fascicles of smooth muscle cells are cut across (c) or cells form cords secondary to hydropic change (d).

Among smooth muscle markers, desmin followed by actin and h-caldesmon are most commonly expressed especially in the spindle areas of the tumor. Remember that smooth muscle tumors may focally express HMB45, thus, when applying immunohistochemistry, the diagnosis of PEComa is made when two melanocytic markers are positive (HMB45, cathepsinK, MelanA) with + / - positivity for muscle markers (desmin, smooth muscle actin, h-caldesmon). As occurs with smooth muscle tumors, some PEComas are associated with adverse outcome if they show $\geq 2$ of the following features: $\geq 5 \mathrm{~cm}$, infiltration, high-grade cytologic features, mitotic rate $\geq 1 / 50 \mathrm{HPFs}$, necrosis, or lymphovascular invasion. ${ }^{88,89}$

Poorly differentiated carcinoma (primary or metastatic) may have eosinophilic or clear cells growing in sheets, cords, or nests but will exhibit, at least focally, glandular or squamous differentiation. The distinction may be more problematic in a biopsy or curettage specimen as foci of better-differentiated carcinoma may not have been sampled. When applying immunohistochemistry to aid in this differential diagnosis it is important to keep in mind that smooth muscle tumors in general, but in particular epithelioid ones, are often positive for epithelial markers including keratins and EMA and may be less often/less extensively positive for muscle markers. ${ }^{93}$ Thus, a panel of antibodies that also includes PAX8, HNF1b, and Napsin A (the latter two if clear cells are present), and more than one smooth muscle marker should be used.98,99-101 Leiomyosarcomas are also typically ER, PR, p16, and p53 positive, thus these markers are not helpful in this scenario. ${ }^{11,31,34,37,73,76,102-104}$

Uterine tumor resembling an ovarian sex-cord tumor shows patterns and cells that may overlap to a striking degree with epithelioid smooth muscle tumors. Their immunohistochemical profile is also quite similar as they are often positive for actin, desmin and to a less extend h-caldesmon and often show keratin (50\%), but only uncommonly EMA $(<10 \%)$ expression. Helpful diagnostic clues include more pronounced epithelial appearance in most UTROSCTs seen as tubular and retiform differentiation, vacuolated cell cytoplasm 

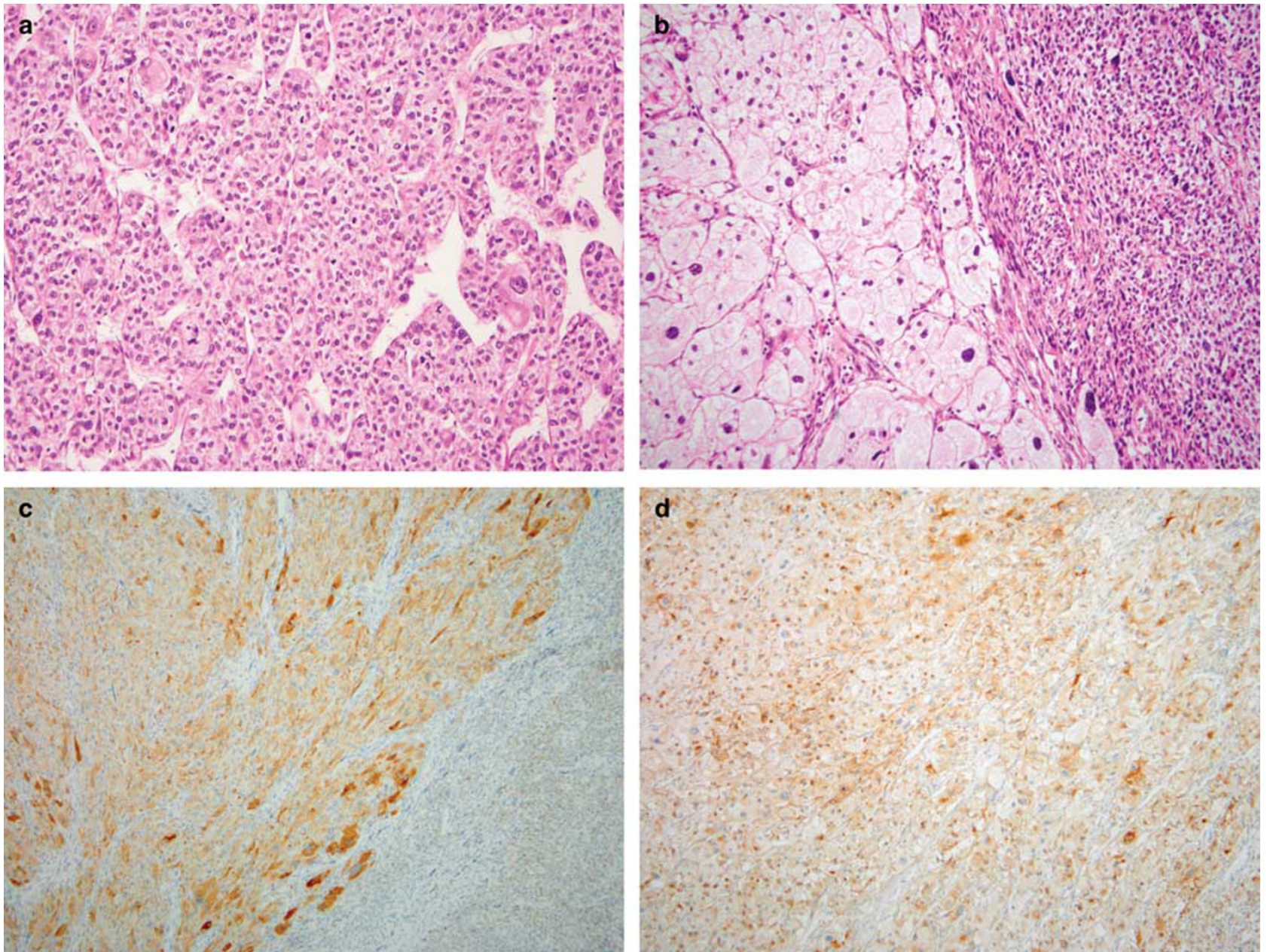

Figure 9 PEComa. The tumor has a nested growth of epithelioid cells associated with a prominent delicate vasculature. Isolated cells with cytologic atypia are noted (a). A spindle morphology or cells with abundant striking clear vacuolated cytoplasm are present (b). The tumor is more positive for Melan A in epithelioid areas (c); CathepsinK shows extensive positivity (d).

(although typically focal), and variable expression of sex-cord stromal markers (inhibin, calretinin, and melan A) ${ }^{105-110}$ and sometimes FOXL2 expression, although without associated mutations. ${ }^{111}$

Intermediate-type trophoblastic tumors have cells with abundant eosinophilic or clear cytoplasm showing variable degree of cytologic atypia and mitotic activity and grow in a diffuse or nested pattern, features that overlap with those seen in epithelioid leiomyosarcomas. These trophoblastic tumors also express cytokeratins, and may express CD10 and p16 as leiomyosarcomas. ${ }^{112-114}$ Placental site trophoblastic tumors have a very characteristic infiltrative growth of single cells or small aggregates of cells that dissect individual muscle fibers and often replace endothelial cells with associated fibrinoid change recapitulating the physiologic implantation site. ${ }^{115,116}$ The finding of islands or nests of cells surrounded by extensive necrosis or hyaline-like matrix that are p63-positive support the diagnosis of epithelioid trophoblastic tumor. ${ }^{117,118}$ Trophoblastic tumors are typically positive for hPL (PSTT > ETT), CK18, and inhibin, markers that not expressed in epithelioid smooth muscle tumors. ${ }^{119-121}$ A history of recent pregnancy or abortion and an elevated serum hCG level may also be helpful, although tumors may occur after years of a pregnancy.

Alveolar soft-part sarcoma is rare in the female genital tract, the uterus being the most common location. Finding an alveolar growth, PAS-positive diastase resistant granules and/or crystals, and TFE3 positivity in the tumor cells supports this diagnosis. ${ }^{114,122,123}$ Epithelioid endometrial stromal sarcoma is an exceedingly rare variant of endometrial stromal tumor in which cells have abundant eosinophilic cytoplasm. ${ }^{124}$ The morphologic and immunohistochemical features discussed in the differential diagnosis between myxoid endometrial stromal sarcoma and leiomyosarcoma can be applied. Melanomas, either primary or metastatic, are rare. Finding of pigment, sometimes a preexistent benign lesion, or prior history may be helpful in making such diagnosis. When in doubt, a panel of antibodies including more than one melanocytic marker is advised. 


\section{Practical Points}

- Inquire about clinical history, especially patient"s age and progestin intake, as it may explain the "potentially worrisome" morphologic features of the smooth muscle tumor.

- Correlate the gross appearance of the tumor with its morphology. A smooth muscle tumor unlikely will be malignant if it grossly has the typical white, firm and whorly cut surface.

- It is important to extensively sample a smooth muscle tumor if an unusual appearance is noted in order to identify morphologic features that will help in its correct classification.

- Pathologists must use caution in interpreting "atypical mitoses" as such in absence of conventional ones, as they are likely to represent karyorrhectic nuclei, typically noted in leiomyomas with bizarre nuclei.

- Evaluate necrosis of uncertain nature in conjunction with nuclear atypia and mitoses, as overlapping appearance can be seen on occasion between tumor cell and infarct-type necrosis. Remember that both benign and malignant smooth muscle tumors may have infarct-type necrosis.

- p16, p53, Ki-67, and other cell cycle regulatory markers are often not helpful in the distinction between leiomyomas with unusual features (mostly leiomyomas with bizarre nuclei) and leiomyosarcoma, as overlap in their expression is common.

- Before classifying a smooth muscle tumor as epithelioid, exclude a pseudoepithelioid appearance given by any of the following: cross section of smooth muscle fascicles, hydropic change often associated with hyalinization, viable areas of smooth muscle neoplasia close to infarct-type necrosis, rhabdoid change, or leiomyomas from pregnant women.

- Criteria for malignancy are hard to define with certainty particularly in epithelioid/myxoid smooth muscle tumors as experience with these tumors is not as extensive as with spindle cell leiomyosarcomas. Thus, sampling as well as exclusion of other entities in the differential diagnosis, is key.

\section{Disclosure/conflict of interest}

The author declares no conflict of interest.

\section{References}

1 Abeler VM, Royne O, Thoresen S et al. Uterine sarcomas in Norway. A histopathological and prognostic survey of a total population from 1970 to 2000 including 419 patients. Histopathology 2009;54: 355-364.

2 Wang WL, Soslow R, Hensley M et al. Histopathologic prognostic factors in stage I leiomyosarcoma of the uterus: a detailed analysis of 27 cases. Am J Surg Pathol 2011;35:522-529.
3 Mayerhofer K, Obermair A, Windbichler G et al. Leiomyosarcoma of the uterus: a clinicopathologic multicenter study of 71 cases. Gynecol Oncol 1999;74: 196-201.

4 Lim D, Wang WL, Lee CH et al. Old versus new FIGO staging systems in predicting overall survival in patients with uterine leiomyosarcoma: a study of 86 cases. Gynecol Oncol 2013;128:322-326.

5 Raut CP, Nucci MR, Wang Q et al. Predictive value of FIGO and AJCC staging systems in patients with uterine leiomyosarcoma. Eur J Cancer 2009;45:2818-2824.

6 Edge SB. American Joint Committee on CancerAJCC Cancer Staging Manual. Springer: New York, USA, 2010;648 p.

7 Prat J. FIGO staging for uterine sarcomas. Int J Gynaecol Obstet 2009;104:177-178.

8 Zivanovic O, Jacks LM, Iasonos A et al. A nomogram to predict postresection 5-year overall survival for patients with uterine leiomyosarcoma. Cancer 2012;118:660-669.

9 Zivanovic O, Leitao MM, Iasonos A et al. Stagespecific outcomes of patients with uterine leiomyosarcoma: a comparison of the international Federation of gynecology and obstetrics and american joint committee on cancer staging systems. J Clin Oncol 2009;27:2066-2072.

10 Iasonos A, Keung EZ, Zivanovic O et al. External validation of a prognostic nomogram for overall survival in women with uterine leiomyosarcoma. Cancer 2013;119:1816-1822.

11 Chiang S, Oliva E. Recent developments in uterine mesenchymal neoplasms. Histopathology 2013;62: 124-137.

12 Oliva E, Carcangiu ML, Carinelli S et al. Mesenchymal tumours In: Kurman RJ, Carcangiu ML, Herrington CS et al. (eds). WHO Classification of Tumours of Female Reproductive Organs. IARC Press: Lyons, France, 2014, p 135-147.

13 Burch DM, Tavassoli FA. Myxoid leiomyosarcoma of the uterus. Histopathology 2011;59:1144-1155.

14 Kindelberger D, Hollowell M, Otis C et al. A clinicopathologic study of ten cases. Mod Pathol 2007;20:203A-204A.

15 King ME, Dickersin GR, Scully RE. Myxoid leiomyosarcoma of the uterus. A report of six cases. Am J Surg Pathol 1982;6:589-598.

16 Kurman RJ, Norris HJ. Mesenchymal tumors of the uterus. VI. Epithelioid smooth muscle tumors including leiomyoblastoma and clear-cell leiomyoma: a clinical and pathologic analysis of 26 cases. Cancer 1976;37:1853-1865.

17 Prayson RA, Goldblum JR, Hart WR. Epithelioid smooth-muscle tumors of the uterus: a clinicopathologic study of 18 patients. Am J Surg Pathol 1997;21: 383-391.

18 Toledo G, Oliva E. Smooth muscle tumors of the uterus: a practical approach. Arch Pathol Lab Med 2008;132:595-605.

19 Toon C, McGahan S, Henderson P et al. Myxoid symplastic leiomyoma of the uterus. Pathology 2006;38:275-277.

20 Salm R, Evans DJ. Myxoid leiomyosarcoma. Histopathology 1985;9:159-169.

21 Veras E, Malpica A, Deavers MT et al. Mitosis-specific marker phospho-histone $\mathrm{H} 3$ in the assessment of mitotic index in uterine smooth muscle tumors: a pilot study. Int J Gynecol Pathol 2009;28:316-321. 
22 Bell SW, Kempson RL, Hendrickson MR. Problematic uterine smooth muscle neoplasms. A clinicopathologic study of 213 cases. Am J Surg Pathol 1994;18: 535-558.

23 Giuntoli RL 2nd, Metzinger DS, DiMarco CS et al. Retrospective review of 208 patients with leiomyosarcoma of the uterus: prognostic indicators, surgical management, and adjuvant therapy. Gynecol Oncol 2003;89:460-469.

24 Akhan SE, Yavuz E, Tecer A et al. The expression of Ki-67, p53, estrogen and progesterone receptors affecting survival in uterine leiomyosarcomas. A clinicopathologic study. Gynecol Oncol 2005;99:36-42.

25 Pautier P, Genestie C, Rey A et al. Analysis of clinicopathologic prognostic factors for 157 uterine sarcomas and evaluation of a grading score validated for soft tissue sarcoma. Cancer 2000;88:1425-1431.

26 Veras E, Zivanovic O, Jacks L et al. "Low-grade leiomyosarcoma" and late-recurring smooth muscle tumors of the uterus: a heterogenous collection of frequently misdiagnosed tumors associated with an overall favorable prognosis relative to conventional uterine leiomyosarcomas. Am J Surg Pathol 2011;35: 1626-1637.

27 Lim D, Alvarez T, Nucci MR et al. Interobserver variability in the interpretation of tumor cell necrosis in uterine leiomyosarcoma. Am J Surg Pathol 2013;37: 650-658.

28 Wang W, Soslow RA, Zannoni G, al e. The utility of tumor cell necrosis in the diagnosis of primary leiomyosarcoma of the uterus: An analysis of 77 cases. Mod Pathol 2006;18:201A.

29 Croce S, Young RH, Oliva E. Uterine leiomyomas with bizarre nuclei: a clinicopathologic study of 59 cases. Am J Surg Pathol 2014;38:1330-1339.

30 Downes KA, Hart WR. Bizarre leiomyomas of the uterus: a comprehensive pathologic study of 24 cases with long-term follow-up. Am J Surg Pathol 1997;21: 1261-1270.

31 Mills AM, Ly A, Balzer BL et al. Cell cycle regulatory markers in uterine atypical leiomyoma and leiomyosarcoma: immunohistochemical study of 68 cases with clinical follow-up. Am J Surg Pathol 2013;37: 634-642.

32 Mittal KR, Chen F, Wei JJ et al. Molecular and immunohistochemical evidence for the origin of uterine leiomyosarcomas from associated leiomyoma and symplastic leiomyoma-like areas. Mod Pathol 2009;22:1303-1311.

33 Bodner-Adler $\mathrm{B}$, Bodner $\mathrm{K}$, Czerwenka $\mathrm{K}$ et al. Expression of p16 protein in patients with uterine smooth muscle tumors: an immunohistochemical analysis. Gynecol Oncol 2005;96:62-66.

34 Chen L, Yang B. Immunohistochemical analysis of p16, p53, and Ki-67 expression in uterine smooth muscle tumors. Int J Gynecol Pathol 2008;27: 326-332.

35 Gannon BR, Manduch M, Childs TJ. Differential Immunoreactivity of p16 in leiomyosarcomas and leiomyoma variants. Int J Gynecol Pathol 2008;27: 68-73.

36 Hakverdi S, Gungoren A, Yaldiz M et al.. Immunohistochemical analysis of p16 expression in uterine smooth muscle tumors. Eur J Gynaecol Oncol 2011;32:513-515.

37 D'Angelo E, Espinosa I, Ali R et al. Uterine leiomyosarcomas: tumor size, mitotic index, and biomarkers
Ki67, and Bcl-2 identify two groups with different prognosis. Gynecol Oncol 2011;121:328-333.

38 O'Neill CJ, McBride HA, Connolly LE et al. Uterine leiomyosarcomas are characterized by high p16, p53 and MIB1 expression in comparison with usual leiomyomas, leiomyoma variants and smooth muscle tumours of uncertain malignant potential. Histopathology 2007;50:851-858.

39 Sung CO, Ahn G, Song SY et al. Atypical leiomyomas of the uterus with long-term follow-up after myomectomy with immunohistochemical analysis for p16INK4A, p53, Ki-67, estrogen receptors, and progesterone receptors. Int J Gynecol Pathol 2009;28: 529-534.

40 Croce S, Chibon F. MED12 and uterine smooth muscle oncogenesis: State of the art and perspectives. Eur J Cancer 2015;51:1603-1610.

41 Je EM, Kim MR, Min KO et al. Mutational analysis of MED12 exon 2 in uterine leiomyoma and other common tumors. Int J Cancer 2012;131:E1044-E1047.

42 McGuire MM, Yatsenko A, Hoffner L et al. Whole exome sequencing in a random sample of North American women with leiomyomas identifies MED12 mutations in majority of uterine leiomyomas. PLoS One 2012;7:e33251.

43 Perot G, Croce S, Ribeiro A et al. MED12 alterations in both human benign and malignant uterine soft tissue tumors. PLoS One 2012;7:e40015.

44 Bertsch E, Qiang W, Zhang Q et al. MED12 and HMGA2 mutations: two independent genetic events in uterine leiomyoma and leiomyosarcoma. Mod Pathol 2014;27:1144-1153.

45 Matsubara A, Sekine S, Yoshida M et al. Prevalence of MED12 mutations in uterine and extrauterine smooth muscle tumours. Histopathology 2013;62:657-661.

46 Schwetye KE, Pfeifer JD, Duncavage EJ. MED12 exon 2 mutations in uterine and extrauterine smooth muscle tumors. Hum Pathol 2014;45:65-70.

47 Reyes C, Karamurzin Y, Frizzell N et al. Uterine smooth muscle tumors with features suggesting fumarate hydratase aberration: detailed morphologic analysis and correlation with S-(2-succino)-cysteine immunohistochemistry. Mod Pathol 2014;27: 1020-1027.

48 Bennett J, Chiang S, Chen YB et al. Leiomyoma with Bizarre Nuclei: Correlation Between Morphology and Fumarate Hydratase/S-(2-Succino)-Cysteine Expression. Mod Pathol 2015;28:276a.

49 Sanz-Ortega J, Vocke C, Stratton P et al. Morphologic and molecular characteristics of uterine leiomyomas in hereditary leiomyomatosis and renal cancer (HLRCC) syndrome. Am J Surg Pathol 2013;37: 74-80.

50 Garg K, Tickoo SK, Soslow RA et al. Morphologic features of uterine leiomyomas associated with hereditary leiomyomatosis and renal cell carcinoma syndrome: a case report. Am J Surg Pathol 2011;35: 1235-1237.

51 Alsolami S, El-Bahrawy M, Kalloger SE et al. Current morphologic criteria perform poorly in identifying hereditary leiomyomatosis and renal cell carcinoma syndrome-associated uterine leiomyomas. Int J Gynecol Pathol 2014;33:560-567.

52 O'Connor DM, Norris HJ. Mitotically active leiomyomas of the uterus. Hum Pathol 1990;21:223-227.

53 Prayson RA, Hart WR. Mitotically active leiomyomas of the uterus. Am J Clin Pathol 1992;97:14-20. 
54 Myles JL, Hart WR. Apoplectic leiomyomas of the uterus. A clinicopathologic study of five distinctive hemorrhagic leiomyomas associated with oral contraceptive usage. Am J Surg Pathol 1985;9: 798-805.

55 Ip PP, Lim D, Cheung AN et al. Immunoexpression of p16 in Uterine Leiomyomas with Infarct Type Necrosis. Mod Pathol 2015;28:291 A.

56 Oliva E, Young RH, Clement PB et al. Cellular benign mesenchymal tumors of the uterus. A comparative morphologic and immunohistochemical analysis of 33 highly cellular leiomyomas and six endometrial stromal nodules, two frequently confused tumors. Am J Surg Pathol 1995;19:757-768.

57 Moinfar F, Azodi M, Tavassoli FA. Uterine sarcomas. Pathology 2007;39:55-71.

58 Chen E, O'Connell F, Fletcher CD. Dedifferentiated leiomyosarcoma: clinicopathological analysis of 18 cases. Histopathology 2011;59:1135-1143.

59 McCluggage WG, Lioe TF, McClelland HR et al. Rhabdomyosarcoma of the uterus: report of two cases, including one of the spindle cell variant. Int J Gynecol Cancer 2002;12:128-132.

60 Baker P, Oliva EIntraoperative Consultation during Gynecologic Pathology (Vagina, Vuolva, Uterine Cervix, and Corpus). In: Marchevsky AM, Abdul Karim FW, Balzer BLeditors. Intraoperative Consultation. Elsevier Saunders: Philadelphia, PA, USA, 2015, p 292-309.

61 Clement PB, Young RH, Scully RE. Diffuse, perinodular, and other patterns of hydropic degeneration within and adjacent to uterine leiomyomas. Problems in differential diagnosis. Am J Surg Pathol 1992;16: 26-32.

62 Chesnais AL, Watkin E, Beurton D et al. Myxoid mesenchymal tumors of uterus: endometrial stromal and smooth muscle tumors, myxoid variant. Ann Pathol 2011;31:152-158.

63 Norris HJ, Hilliard GD, Irey NS. Hemorrhagic cellular leiomyomas ("apoplectic leiomyoma") of the uterus associated with pregnancy and oral contraceptives. Int J Gynecol Pathol 1988;7:212-224.

64 Clement PB, Young RH, Scully RE. Intravenous leiomyomatosis of the uterus. A clinicopathological analysis of 16 cases with unusual histologic features. Am J Surg Pathol 1988;12:932-945.

65 Ip PP, Tse KY, Tam KF. Uterine smooth muscle tumors other than the ordinary leiomyomas and leiomyosarcomas: a review of selected variants with emphasis on recent advances and unusual morphology that may cause concern for malignancy. Adv Anat Pathol 2010;17:91-112.

66 Oliva E, Young RH, Clement PB et al. Myxoid and fibrous endometrial stromal tumors of the uterus: a report of 10 cases. Int J Gynecol Pathol 1999;18: 310-319.

67 Yilmaz A, Rush DS, Soslow RA. Endometrial stromal sarcomas with unusual histologic features: a report of 24 primary and metastatic tumors emphasizing fibroblastic and smooth muscle differentiation. Am J Surg Pathol 2002;26:1142-1150.

68 Oliva E. Cellular mesenchymal tumors of the uterus: a review emphasizing recent observations. Int J Gynecol Pathol 2014;33:374-384.

69 Lee CH, Marino-Enriquez A, Ou W et al. The clinicopathologic features of YWHAE-FAM22 endometrial stromal sarcomas: A histologically high-grade and clinically aggressive tumor. Am J Surg Pathol 2012;36: 641-653.

70 Baker P, Oliva E. Endometrial stromal tumours of the uterus: a practical approach using conventional morphology and ancillary techniques. J Clin Pathol 2007;60:235-243.

71 Nucci MR, O'Connell JT, Huettner PC et al. h-Caldesmon expression effectively distinguishes endometrial stromal tumors from uterine smooth muscle tumors. Am J Surg Pathol 2001;25:455-463.

72 Lee CH, Ali RH, Rouzbahman M et al. Cyclin D1 as a diagnostic immunomarker for endometrial stromal sarcoma with YWHAE-FAM22 rearrangement. Am J Surg Pathol 2012;36:1562-1570.

73 Leitao MM, Soslow RA, Nonaka D et al. Tissue microarray immunohistochemical expression of estrogen, progesterone, and androgen receptors in uterine leiomyomata and leiomyosarcoma. Cancer 2004;101:1455-1462.

74 Loddenkemper C, Mechsner S, Foss HD et al. Use of oxytocin receptor expression in distinguishing between uterine smooth muscle tumors and endometrial stromal sarcoma. Am J Surg Pathol 2003;27: 1458-1462.

75 Oliva E, Young RH, Amin MB et al. An immunohistochemical analysis of endometrial stromal and smooth muscle tumors of the uterus: a study of 54 cases emphasizing the importance of using a panel because of overlap in immunoreactivity for individual antibodies. Am J Surg Pathol 2002;26: 403-412.

76 Leitao MM Jr, Hensley ML, Barakat RR et al. Immunohistochemical expression of estrogen and progesterone receptors and outcomes in patients with newly diagnosed uterine leiomyosarcoma. Gynecol Oncol 2012;124:558-562.

77 Bodner K, Bodner-Adler B, Kimberger $\mathrm{O}$ et al. Estrogen and progesterone receptor expression in patients with uterine leiomyosarcoma and correlation with different clinicopathological parameters. Anticancer Res 2003;23:729-732.

78 Mittal K, Demopoulos RI. MIB-1 (Ki-67), p53, estrogen receptor, and progesterone receptor expression in uterine smooth muscle tumors. Hum Pathol 2001;32: 984-987.

79 Gilks CB, Taylor GP, Clement PB. Inflammatory pseudotumor of the uterus. Int J Gynecol Pathol 1987;6:275-286.

80 Parra-Herran C, Quick CM, Howitt BE et al. Inflammatory myofibroblastic tumor of the uterus: clinical and pathologic review of 10 cases including a subset with aggressive clinical course. Am J Surg Pathol 2015;39:157-168.

81 Rabban JT, Zaloudek CJ, Shekitka KM et al. Inflammatory myofibroblastic tumor of the uterus: a clinicopathologic study of 6 cases emphasizing distinction from aggressive mesenchymal tumors. Am J Surg Pathol 2005;29:1348-1355.

82 Veras E, Junkins-Hopkins JM, Marinis S et al. Myometrial myxoidosis: a report of 2 cases of a distinctive type of secondary myometrial hypertrophy in patients with lupus erythematosus. Int J Gynecol Pathol 2009;28:164-171.

83 Pugh A, McCluggage WG, Hirschowitz L. Multifocal uterine myxoid change: a newly recognized association with neurofibromatosis type 1. Int J Gynecol Pathol 2012;31:580-583. 
84 Raspollini MR, Pinzani P, Simi L et al. Uterine leiomyosarcomas express KIT protein but lack mutation(s) in exon 9 of c-KIT. Gynecol Oncol 2005;98: 334-335.

85 Rushing RS, Shajahan S, Chendil D et al. Uterine sarcomas express KIT protein but lack mutation(s) in exon 11 or 17 of c-KIT. Gynecol Oncol 2003;91:9-14.

86 Novelli M, Rossi S, Rodriguez-Justo M et al. DOG1 and CD117 are the antibodies of choice in the diagnosis of gastrointestinal stromal tumours. Histopathology 2010;57:259-270.

87 Fadare O. Perivascular epithelioid cell tumor (PEComa) of the uterus: an outcome-based clinicopathologic analysis of 41 reported cases. Adv Anat Pathol 2008;15:63-75.

88 Folpe AL, Mentzel T, Lehr HA et al. Perivascular epithelioid cell neoplasms of soft tissue and gynecologic origin: a clinicopathologic study of 26 cases and review of the literature. Am J Surg Pathol 2005;29: 1558-1575.

89 Schoolmeester JK, Howitt BE, Hirsch MS et al. Perivascular epithelioid cell neoplasm (PEComa) of the gynecologic tract: clinicopathologic and immunohistochemical characterization of 16 cases. Am J Surg Pathol 2014;38:176-188.

90 Vang R, Kempson RL. Perivascular epithelioid cell tumor ('PEComa') of the uterus: a subset of HMB-45positive epithelioid mesenchymal neoplasms with an uncertain relationship to pure smooth muscle tumors. Am J Surg Pathol 2002;26:1-13.

91 Conlon N, Soslow RA, Murali R. Perivascular epithelioid tumours (PEComas) of the gynaecological tract. J Clin Pathol 2015;68:418-426.

92 Rao Q, Cheng L, Xia QY et al. Cathepsin K expression in a wide spectrum of perivascular epithelioid cell neoplasms (PEComas): a clinicopathological study emphasizing extrarenal PEComas. Histopathology 2013;62:642-650.

93 Iwata J, Fletcher CD. Immunohistochemical detection of cytokeratin and epithelial membrane antigen in leiomyosarcoma: a systematic study of 100 cases. Pathol Int 2000;50:7-14.

94 Silva EG, Deavers MT, Bodurka DC et al. Uterine epithelioid leiomyosarcomas with clear cells: reactivity with HMB- 45 and the concept of PEComa. Am J Surg Pathol 2004;28:244-249.

95 Fisher C. The value of electronmicroscopy and immunohistochemistry in the diagnosis of soft tissue sarcomas: a study of 200 cases. Histopathology 1990;16:441-454

96 Agaram NP, Sung YS, Zhang L et al. Dichotomy of Genetic Abnormalities in PEComas With Therapeutic Implications. Am J Surg Pathol 2015;39:813-825.

97 Schoolmeester JK, Dao LN, Sukov WR et al. TFE3 translocation-associated perivascular epithelioid cell neoplasm (PEComa) of the gynecologic tract: morphology, immunophenotype, differential diagnosis. Am J Surg Pathol 2015;39:394-404.

98 Laury AR, Perets R, Piao $\mathrm{H}$ et al. A comprehensive analysis of PAX8 expression in human epithelial tumors. Am J Surg Pathol 2011;35:816-826.

99 Fadare O, Zhao C, Khabele D et al. Comparative analysis of Napsin A, alpha-methylacyl-coenzyme A racemase (AMACR, P504S), and hepatocyte nuclear factor 1 beta as diagnostic markers of ovarian clear cell carcinoma: an immunohistochemical study of 279 ovarian tumours. Pathology 2015;47:105-111.
100 Iwamoto M, Nakatani Y, Fugo K et al. Napsin A is frequently expressed in clear cell carcinoma of the ovary and endometrium. Hum Pathol 2015;46: 957-962.

101 Lim D, Ip PP, Cheung AN et al. Immunohistochemical Comparison of Ovarian and Uterine Endometrioid Carcinoma, Endometrioid Carcinoma With Clear Cell Change, and Clear Cell Carcinoma. Am J Surg Pathol 2015;39:1061-1069.

102 Anderson SE, Nonaka D, Chuai S et al. p53, epidermal growth factor, and platelet-derived growth factor in uterine leiomyosarcoma and leiomyomas. Int J Gynecol Cancer 2006;16:849-853.

103 Blom R, Guerrieri C, Stal O et al. Leiomyosarcoma of the uterus: A clinicopathologic, DNA flow cytometric, p53, and mdm-2 analysis of 49 cases. Gynecol Oncol 1998;68:54-61.

104 Leiser AL, Anderson SE, Nonaka D et al. Apoptotic and cell cycle regulatory markers in uterine leiomyosarcoma. Gynecol Oncol 2006;101:86-91.

105 Clement PB, Scully RE. Uterine tumors resembling ovarian sex-cord tumors. A clinicopathologic analysis of fourteen cases. Am J Clin Pathol 1976;66:512-525.

106 Czernobilsky B. Uterine tumors resembling ovarian sex cord tumors: an update. Int J Gynecol Pathol 2008;27:229-235.

107 de Leval L, Lim GS, Waltregny D et al. Diverse phenotypic profile of uterine tumors resembling ovarian sex cord tumors: an immunohistochemical study of 12 cases. Am J Surg Pathol 2010;34: 1749-1761.

108 Hurrell DP, McCluggage WG. Uterine tumour resembling ovarian sex cord tumour is an immunohistochemically polyphenotypic neoplasm which exhibits coexpression of epithelial, myoid and sex cord markers. J Clin Pathol 2007;60:1148-1154.

109 Irving JA, Carinelli S, Prat J. Uterine tumors resembling ovarian sex cord tumors are polyphenotypic neoplasms with true sex cord differentiation. Mod Pathol 2006;19:17-24.

110 Krishnamurthy S, Jungbluth AA, Busam KJ et al. Uterine tumors resembling ovarian sex-cord tumors have an immunophenotype consistent with true sex-cord differentiation. Am J Surg Pathol 1998;22: 1078-1082.

111 Chiang S, Staats PN, Senz J et al. FOXL2 mutation is absent in uterine tumors resembling ovarian sex cord tumors. Am J Surg Pathol 2015;39:618-623.

112 Chew I, Post MD, Carinelli SG et al. p16 expression in squamous and trophoblastic lesions of the upper female genital tract. Int J Gynecol Pathol 2010;29: 513-522.

113 Mao TL, Seidman JD, Kurman RJ et al. and p16 immunoreactivity in epithelioid trophoblastic tumoran aid in differential diagnosis. Am J Surg Pathol 2006;30:1105-1110.

114 Ordi J, Romagosa C, Tavassoli FA et al. CD10 expression in epithelial tissues and tumors of the gynecologic tract: a useful marker in the diagnosis of mesonephric, trophoblastic, and clear cell tumors. Am J Surg Pathol 2003;27:178-186.

115 Shih IM, Kurman RJ. The pathology of intermediate trophoblastic tumors and tumor-like lesions. Int J Gynecol Pathol 2001;20:31-47.

116 Young RH, Kurman RJ, Scully RE. Proliferations and tumors of intermediate trophoblast of the placental site. Semin Diagn Pathol 1988;5:223-237. 
117 Shih IM, Kurman RJ. Epithelioid trophoblastic tumor: a neoplasm distinct from choriocarcinoma and placental site trophoblastic tumor simulating carcinoma. Am J Surg Pathol 1998;22:1393-1403.

118 Shih IM, Kurman RJ. p63 expression is useful in the distinction of epithelioid trophoblastic and placental site trophoblastic tumors by profiling trophoblastic subpopulations. Am J Surg Pathol 2004; 28:1177-1183.

119 Kalhor N, Ramirez PT, Deavers MT et al. Immunohistochemical studies of trophoblastic tumors. Am J Surg Pathol 2009;33:633-638.

120 Kurman RJ, Young RH, Norris HJ et al. Immunocytochemical localization of placental lactogen and chorionic gonadotropin in the normal placenta and trophoblastic tumors, with emphasis on intermediate trophoblast and the placental site trophoblastic tumor. Int J Gynecol Pathol 1984;3:101-121.
121 Shih IM, Kurman RJ. Immunohistochemical localization of inhibin-alpha in the placenta and gestational trophoblastic lesions. Int J Gynecol Pathol 1999;18: 144-150.

122 Nielsen GP, Oliva E, Young RH et al. Alveolar softpart sarcoma of the female genital tract: a report of nine cases and review of the literature. Int J Gynecol Pathol 1995;14:283-292.

123 Roma AA, Yang B, Senior ME et al. TFE3 immunoreactivity in alveolar soft part sarcoma of the uterine cervix: case report. Int J Gynecol Pathol 2005;24: 131-135.

124 Oliva E, Clement PB, Young RH. Epithelioid endometrial and endometrioid stromal tumors: a report of four cases emphasizing their distinction from epithelioid smooth muscle tumors and other oxyphilic uterine and extrauterine tumors. Int J Gynecol Pathol 2002;21:48-55. 